\title{
Corrosion behaviour of rebars 1.4003 in cracks of RC structures containing chlorides
}

\author{
Christoph Dauberschmidt ${ }^{1 *}$, Andreas Fraundorfer ${ }^{1}$ \\ ${ }^{1}$ Munich University of Applied Sciences, Department of Civil Engineering, Karlstrasse 6, 80333 Munich, Germany
}

\begin{abstract}
The durability of chloride exposed reinforced concrete components is decisively determined by the corrosion behaviour of the reinforcement in the crack containing chlorides. In this case, high corrosion rates may occur using conventional rebar steel, which can lead to a significant cross-sectional loss of the rebar in a short period of time. One possible way to minimise the risk of corrosion in cracks containing chlorides is to use stainless rebars. Here, mostly expensive stainless steels of the material numbers $1.4571,1.4401$ etc. are used. An efficient alternative is the use of Chromium reinforcing steels (e.g. X2CrNi12) 1.4003. Corrosion tests on cracked reinforced concrete beams with chloride exposure and different chloride concentrations have been carried out in the laboratory of the University of Applied Sciences in Munich. The results of these investigations show a significant increase of the critical corrosion inducing chloride content of the rebars within the cracks. These results will be discussed in regard of the durability of reinforced concrete structures with Chromium reinforcing steels and cracked RC-structures in parking decks and floor slabs.
\end{abstract}

\section{Introduction}

The durability of reinforced concrete components is mainly determined by the structural design, the resistance and the impermeability of the concrete, as well as the environmental conditions.

Reinforcing steel in concrete is protected by the high alkalinity of the concrete. The basic environment of the concrete pore solution leads to the formation of a passive layer on the surface of the steel, which ensures its corrosion resistance. To assure the long-term corrosion protection of reinforced concrete components, a sufficiently dense and thick concrete cover is required.

Corrosion on the reinforcing steel, which can deteriorate the construction component, is initiated when the passive layer is destroyed. The most common causes of depassiviation under normal environmental conditions result from either carbonation or chloride-induced corrosion. Unlike carbonation-induced corrosion, which is only relevant in the case of insufficient concrete cover, imperfections (for example, compaction faults) and very wide cracks, chloride-induced corrosion can also occur if the structure is carried out in conformity with the relevant standards. Chloride-induced corrosion is particularly dangerous in regard to the load-bearing capacity of a component, as it usually results in a very local attack of the steel, whereby a significant loss of the cross-section area of the reinforcing steel can occur after short exposition periods. Crack areas into which chlorides penetrate rapidly are particularly endangered due to the short introduction phase.
Chloride exposure usually takes place due to deployed de-icing salt during the winter months (for example in bridges and underground garages). However, chloride ingress in structures may occur from seawater (e.g., in harbour structures and bridge pylons in seawater) and other exposures (e.g., PVC fires, industrial plants, and swimming pools).

As soon as the concrete at the level of the reinforcement is contaminated with chlorides in a critical concentration, expensive repairs may become necessary. Even small quantities of chloride-containing waters in the crack area can lead to corrosion initiation.

There are several strategies to ensure the durability of chloride exposed RC-structures. In most cases, a maintenance-intensive coating or a seal is applied on the concrete surface in order to prevent chloride from entering the concrete over the period of use. If the coating systems are not properly maintained and cracking remains undetected, even one winter period [1] may be sufficient to initiate corrosion in the component due to the chloride ingress that occurred. According to [2], there is a threshold value of $0.5 \mathrm{Cl}^{-} / \mathrm{c}$ by mass at the rebar. If this value is exceeded, an expert planner should assess the risk of corrosion. This threshold value is considered to be the lower limit for an corrosion inducing chloride content and it refers to unalloyed reinforcing steel.

One strategy to minimise the risk of corrosion is to use corrosion resistant reinforcement (common: stainless steel or GRP reinforcement). While GRP reinforcement is more cost-intensive than unalloyed reinforcing steel 
and bending on the construction site is no longer possible, the use of common high-alloy, austenitic stainless steels 1.4571 and 1.4401 is even more expensive (about a factor of 10 to unalloyed reinforcing steel) and only economically in specific cases.

Another alternative is the use of the much cheaper, high-alloy, ferritic chromium steel 1.4003. The corrosion resistance of this reinforcing steel (which is available on the market) in chloride-containing cracks of reinforced concrete structures is currently the subject of research at the Munich University of Applied Sciences.

\section{Unalloyed and alloyed reinforcing bars}

Commonly, non-alloyed reinforcing steels of the material numbers 1.0438 (B500A, normal ductility) or 1.0439 (B500B, high ductility) are used [3].

In order to achieve "rust-free"-performance under normal environmental conditions, a high part of chromium $(10.5 \%$ and more [4], but in practice only above approximately 12\%) is required. Such high chromium steels form a protective passive layer of chromium oxides on the steel surface. Depending on the type and content of alloying elements, as well as the production, stainless steels in various types of microstructures (ferrite, austenite, martensite, a mixture of austenite and ferrite (duplex steel) or a mixture of ferrite and martensite (dual-phase steel)) may be present in regards to the steric configuration of atoms [5]. This will also influence the tendency to corrosion, hardness and firmness among others.

Austenitic alloying elements are e.g. nickel, carbon, nitrogen and manganese. Chromium and molybdenum are two representatives of the ferrite-stabilizing alloying elements.

For pitting and crevice corrosion of high-alloy stainless steels in chloride-containing media, the socalled Pitting Resistance Equivalent Number (PREN) can be a decisive factor:

$$
\mathrm{PREN}=\% \mathrm{Cr}+3.3 \cdot \% \mathrm{Mo}+16 \cdot \% \mathrm{~N}
$$

In austenitic materials nitrogen is used specifically in regard to corrosive resistance as an alloying element. However, its limited solubility in the microstructure limits its acceptability. In addition, as can be seen from the PREN, the molybdenum content takes a decisive role in the resistance in a chloride-containing environment [6]. However, as the test results from [5] shown below in Tab. 2, the surface treatment in the production also has an significant influence on the corrosion resistance. Thus, the PREN is a useful utility, but should not be considered exclusively.

A characteristic of austenitic steel is the coefficient of thermal expansion, which is higher by the factor of 1.5 compared to ferritic steels. As a result, theoretically, tensions and disturbances can occur at high contents of reinforcement and high temperature fluctuations. In practice, however, such phenomena have not been observed [7].
The reinforcement steel investigated in the context of these preliminary tests can be assigned to the material number 1.4003, material short name $\mathrm{X} 2 \mathrm{CrNi} 12$ according to [8]. The material number 1.4003 describes a corrosion-resistant, high-alloy, ferritic chromium steel with 10.5 to $12.5 \%$ chromium content and addition of nickel. The amount of carbon is $0.02 \%$. The designation $\mathrm{X}$ stands for the mean alloy content of an element of at least 5\% [8]. Compared to the more common stainless steel reinforcements made of chromium-nickel steels, such as 1.4401 (X5CrNiMo17-12-2), molybdenum is not used as alloying element in the 1.4003. The chromium content is reduced. Nickel is added only to $1 \%$, which makes the steel significantly cheaper than the usual austenite stainless steel.

In the specific case of the stainless steel examined here ("Top12") is a ferritic steel with at least $12 \%$ chromium content. The manufacturer's information on the composition is given in Tab. $\mathbf{1}$.

Tab. 1. Composition of Top12-500 according to [9]

\begin{tabular}{|c|c|c|c|c|c|c|c|c|}
\hline & $\mathbf{C}$ & $\mathbf{S i}$ & $\mathbf{M n}$ & $\mathbf{P}$ & $\mathbf{S}$ & $\mathbf{C r}$ & $\mathbf{N i}$ & $\mathbf{N}$ \\
\cline { 2 - 9 } & \multicolumn{10}{|c|}{$\%$} \\
\hline & & & & max. & max. & min. & & \\
Ø & 0.015 & 0.7 & 0.5 & 0.025 & 0.005 & 12.0 & 0.5 & 0.02 \\
\hline
\end{tabular}

Using X-ray fluorescence analysis the tested steels at the University of Applied Sciences Munich had a chromium content of approx. $12.5 \%$.

The structure of the steel is not austenite due to the significantly lower nickel content. This makes the steel less resistant in regard to pitting corrosion in media containing chloride compared to $1.4571,1.4401$. Due to the nevertheless high chromium content of at least $12 \%$ Top 12 has a significantly better corrosion resistance than unalloyed reinforcing steel with simultaneously higher yield stress and strength. The resistance against stress corrosion in chloride-containing environment is commonly higher for ferritic chromium steels compared to austenitic chromium-nickel steels (very high nickel contents above about $20 \%$ excluded).

A combination made of stainless steel reinforcement and unalloyed reinforcing steel (mixed reinforcement) in the concrete component does not lead to any incompatibility due to the occurrence of contact corrosion. As long as the unalloyed reinforcing steel is sufficiently passivated by the alkalinity of the concrete, the rest potential of stainless steel and unalloyed steel are almost identical, which means that no anodic and cathodic areas can be formed [10].

For highly alloyed steel the high corrosion-resistance is based on the formation of a very stable passive layer of chromium oxides, which is stable over a wide range of pHs and exposures. Compared with unalloyed reinforcing steel, corrosion initiation only takes place under significantly more severe exposure conditions leading to dissolution of the passive layer, just like conventional reinforcing steel if losing its alkaline environment. However, as soon as the passive layer of the high-alloy steel is deteriorated, a more localized depassivation usually occurs compared to normal 
reinforcing steel. The corrosion rate of high-alloyed stainless steels is lower than that of unalloyed steel, but the loss of cross section is comparable [11]. In addition, with smaller pittings, poorer aeration of the electrolyte takes place in the pitting, resulting in additional acidification which further enhances the steel removal.

In [10] tests have been carried out on welded reinforcing steels in carbonated and non-carbonated normal and lightweight concrete with and without chloride exposure. A 1.4003 (X2Cr11) has also been tested. In carbonated concrete without simultaneous chloride input, the 1.4003 proved as resistant.

However, for welded steels with high chromium content, chromium depletion can occur around the weld zone, as chromium carbides precipitate in the hot material with the carbon content present in the steel. As a result, the passive layer formation is hindered at this point resulting in a decrease of the corrosion resistance in the edge region of the weld. In [10], it was found that welded 1.4003 samples which were exposed for 0.5 years in a concrete with a chloride content of $2.5 \% / c$ by mass, significant pitting was observed at the edge zone of the weld.

On lollipop tests in mortars published by [12], unalloyed and low-alloyed reinforcing steels were tested in regard to their critical chloride content. In [5], the tests were compared with the results on samples from 1.4003 ("Top12"), which were carried out in cementitious mortars with CEM I and CEM II / B-M (S-T) cements (blast-furnace slag and slate). The 1.4003 was tested with and without mill scale. The results are summarised in Tab. 2.

Tab. 2. Average critical chloride content $\% /$ binder by mass [5]

\begin{tabular}{|c|c|c|c|}
\hline \multirow{2}{*}{} & B500B & $\begin{array}{c}\mathbf{1 . 4 0 0 3} \\
\text { with } \\
\text { mill scale }\end{array}$ & $\begin{array}{c}\mathbf{1 . 4 0 0 3} \\
\text { without } \\
\text { mill scale }\end{array}$ \\
\cline { 2 - 4 } & \multicolumn{3}{|c|}{ Average critical chloride content \%/b by mass } \\
\hline \hline CEM I & 1.25 & 2.05 & 4.90 \\
\hline CEM II & 1.76 & 3.84 & 5.97 \\
\hline
\end{tabular}

Contrary to the expectation, the critical chloride contents in the CEM II samples were higher than in the CEM I samples. This fact was presumed in a longer prepassivation period of the CEM II samples. Also clearly visible is the negative influence of the mill scale. However, this is active removed in the actual process by pickling.

In [13], critical chloride values were determined under practical stress conditions on samples taken from the Naxberg tunnel. The steel types B500B, 1.4003 (with mill scale) and duplex steel 1.4462 were tested. Various concrete and concrete coverages were recorded, whereby the small concrete coverages were partially carbonated.

The following critical total chloride contents (based on the content of binder) were determined:
For duplex steel $\left(\mathrm{C}_{\text {crit }}>3 \% / \mathrm{b}\right.$ by mass $)$ no corrosion could be detected. These results are similar to the results of laboratory experiments in [11]. At the same time, a clear influence of the mill scale of 1.4003 on the corrosion resistance was also found.

\section{Target of the experiments carried out}

As shown, there are numerous studies on the corrosion behaviour of reinforcing steels with the material number 1.4003 in chloride-containing concrete. However, so far only a few tests have been carried out on the corrosion behaviour of these rebars in chloride-containing cracks. This corrosive behaviour in cracks is of high practical relevance: for uncracked RC-structure in chloride exposure a durability within the initiation phase of more than 50 years can be achieved by the targeted selection of certain cements or concrete mixtures, but the formation of cracks in which chlorides can penetrate leads to a high probability of corrosion of the reinforcement crossing the cracks.

Actually the strategy mainly used is to apply a crackbridging coating on the concrete surface causing high costs to maintenance and service. Also, at high water pressures from outside, bubbles and detachments may arise.

Thus, the use of a 1.4003 stainless steel with proven sufficient corrosion resistance in chloride-exposed cracks could provide an economical and robust construction of e.g. underground parking floor slabs.

\section{Test Setup}

As preliminary tests, reinforced concrete beams with a predetermined breaking point were created as part of a master thesis [14]. Reinforced concrete samples of 1.4003 (Top12) and as reference 1.0439 (B500B) carbon steel were investigated. The cracks of the specimens were exposed to chloride solutions of different concentrations in order to determine the range of chloride content leading to corrosion initiation.

To improve the visual control possibilities of the reinforcement at the end of the test and to govern the crack initiation, the steels were grinded at the crack area by removing the ribbing, tapering and degreasing. For each reinforced concrete beam, a reinforcing bar was embedded centrally. The concrete bars received circumferentially a desired cracks joint by inserting chamfer strips. The steel was installed at both ends with over-stand to subsequently create a separation crack at the desired cracks joint by centric pulling in the testing machine until a small yield deformation occurred, see Fig. 1. According to [15] the yield deformation could lead to a slight higher corrosion resistance of the chromium steel. This circumstance was tolerated due to the preliminary tests.

B500B: $\quad 0.4$ to $0.9 \% / \mathrm{b}$ by mass

1.4003: 0.9 to $1.4 \% / \mathrm{b}$ by mass. 


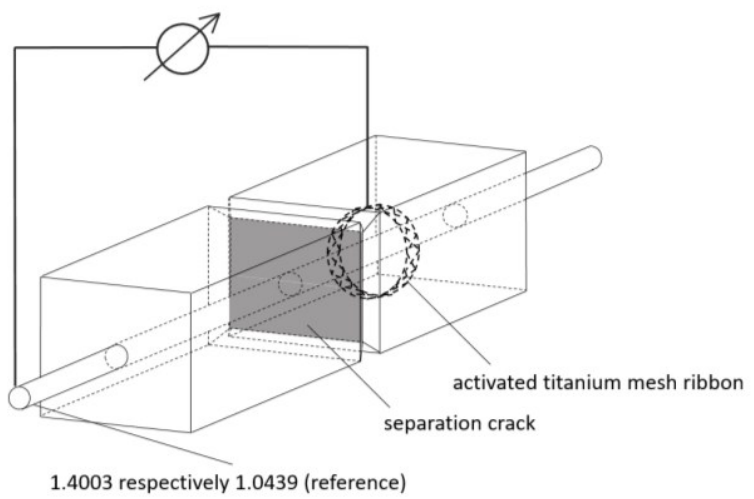

Fig. 1. Sketch of test specimen design

To prevent corrosion due to carbonation at the concrete edge zone, the reinforcing steel was coated in the overstanding area.

As a counter electrode, a ring of an activated titanium mesh ribbon was used. The distance to the reinforcement was ensured by a plastic spacer, cf. Fig. 2.

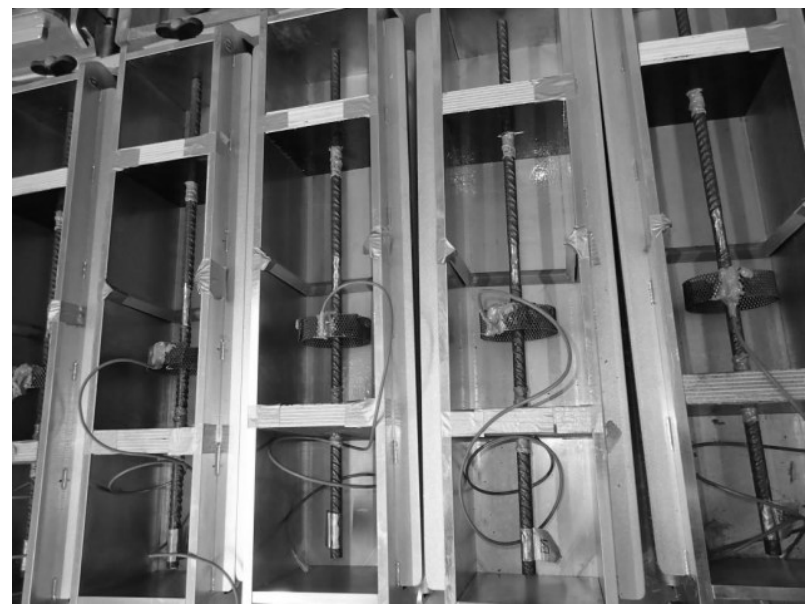

Fig. 2. Specimen with activated titanium mesh ribbon electrode

The connection points of the measuring cables were also provided with a PU coating to prevent contact corrosion.

For the concrete design a CEM I $42.5 \mathrm{~N}$ cement with $\mathrm{a} \mathrm{w} / \mathrm{c}$ ratio $=0.55$ and an $\mathrm{A} / \mathrm{B} 8$ grading curve was used.

After hardening of the concrete, a separation crack was produced in the testing machine $\left(\mathrm{w}_{\mathrm{k}}=1.0 \mathrm{~mm}\right)$ reaching the yielding area of the steel. The large separation crack width was chosen for a rapid test procedure in order to ensure defined water ingress and a sufficient oxygen access whilst water application. As the leaching of pore water is restricted in such wide cracks, the test is on the safe side, cf. Fig. 3.

The cracks were exposed with chloride-containing water after a sufficient hydration phase of 28 days. The following information on total chloride content is given in percentage by mass based on the cement content $[\% / \mathrm{c}$ by mass].

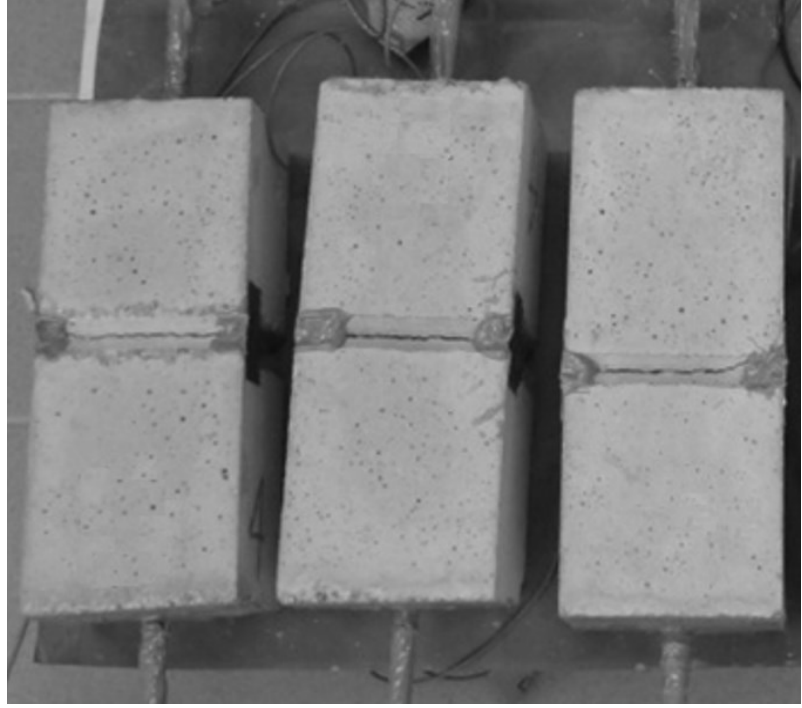

Fig. 3. Test specimen with created separation cracks

\section{Test Procedures}

The exposure with chlorides was carried out with $\mathrm{NaCl}$ solutions in different concentrations ponding the cracks from upside, with laterally dammed crack area. As chloride ions ingressing the crack, they could diffuse from the crack into the concrete. Moreover the main ingress process is likely to be "piggyback transport" by capillary suction as the specimen were stored in dry conditions in the meantime.

In the thesis of Tang [16], with regard to seawaterexposed concrete components, a regression was established between (permanently) existing chloride solution on the concrete surface and the resulting chloride content (diffusion-controlled) in the cementmatrix. Additionally the proportion of free and bound chlorides depending on the total chloride content, based on the cement content, was also determined, s. Fig. 4.

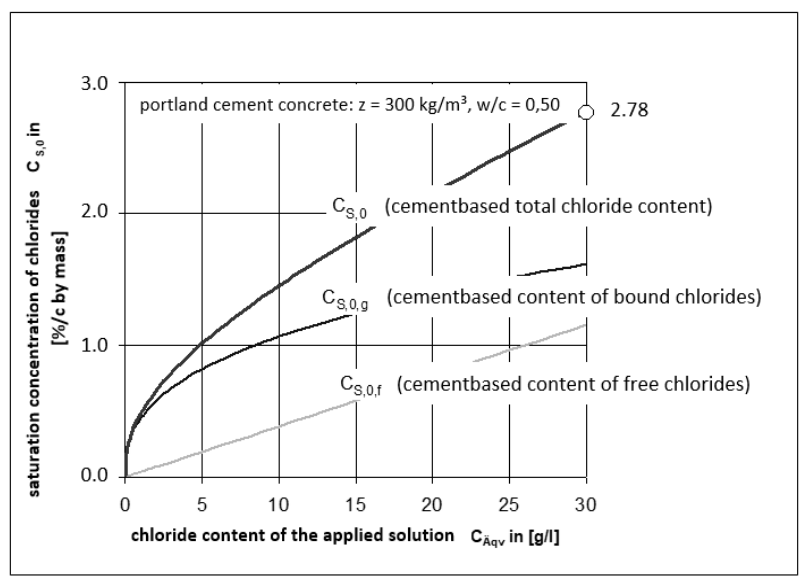

Fig. 4. Chloride content in concrete as a function of the applied chloride solution, representation according to [17], calculated according to [16]

Based on the results according to [16], the aim of the presented test procedure was to set various and practical steps of the total chloride content in concrete up to $7 \% / \mathrm{c}$ 
by mass. One specimen per steel sample was exposed to chloride-free tap water as reference. As the function in Fig. 4 is limited to about $3 \%$ c by mass (with cement content $300 \mathrm{~kg} / \mathrm{m}^{3}, \mathrm{w} / \mathrm{c}=0.50$ ), the values for higher chloride contents have been extrapolated accordingly. Remarkable in Fig. 5 are the very high chloride concentrations of the aqueous solution, which are necessary to reach the high chloride contents in concrete (maximum solubility of $\mathrm{Cl}$ - for $\mathrm{NaCl}$ in $\mathrm{H}_{2} \mathrm{O}$ at $20^{\circ} \mathrm{C}$ : $217 \mathrm{~g} / 1)$.

In regular cycles, the specimens in the cracked area were exposed with the respective chloride-containing solution. This exposure period was followed by a several-day drying phase. Immediately before each water treatment, the corrosion currents were measured. Eighty days after the first exposure, the samples were stored dry for about half a year without further exposure. Finally
For the correct determination of the very small element current, a potentiostat was used, which was switched as Zero Resistance Amperemeter (ZRA). For this measuring arrangement, a two-electrode arrangement is used, wherein a separate reference electrode for potential detection is dispensed with. The counter-electrode is used as a reference at the same time, cf. Fig. 6. At the beginning of the measurement, the resting potential between counter sense (activated titanium mesh ribbon) and working sense (1.4003 or $\mathrm{B} 500 \mathrm{~B})$ is determined. After that, the potential difference between the working and counter electrode is regulated and held to zero. The necessary power is recorded over time. The longer the measurement with a short-circuit between rebar and titanium lasts, the more the "short-circuit current" converges to the element current that would permanently flow with a permanent

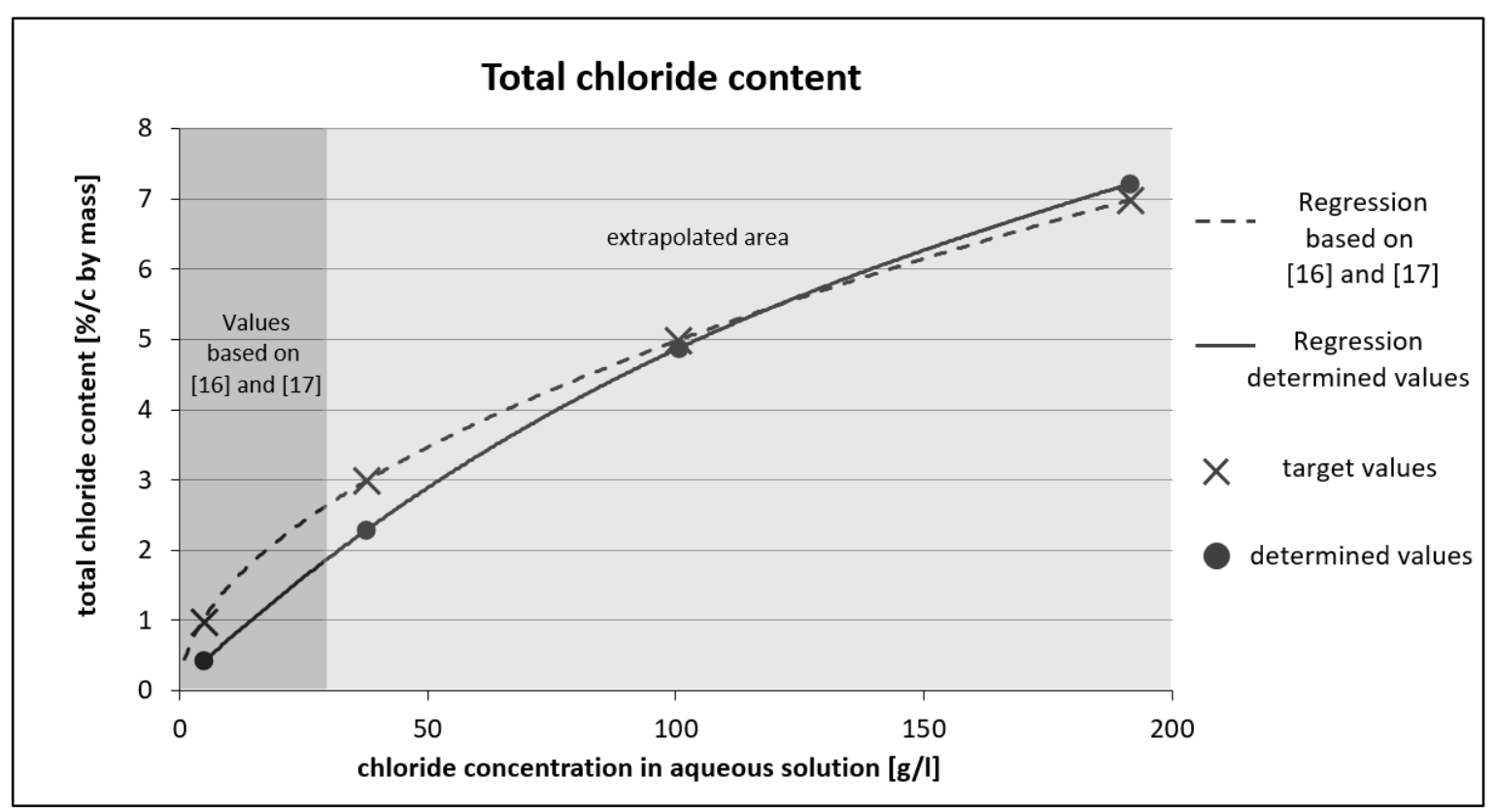

Fig. 5. Comparison of the calculated chloride content according to [17] with [16] and determined values in these experiments

after a last corrosion current measurement, the specimens were split, the rebars dismounted and cleaned for visual assessment.

The correct corrosion current density of the anode cannot be determined by the element corrosion current measurement between rebar and titanium mesh, as part of the cathodic reaction takes place on the anode, too and as the area of the anode is unknown [18]. Therefore the measured current between the supposed anode (rebar) and the cathode (titanium) is defined to be the "element current". Approximately this element current is equated to the corrosion current. After each element-current measurement, the absolute $\mathrm{AC}$ resistance (impedance) at $1 \mathrm{kHz}$ measurement frequency was determined. This value is used for correlation with the element-currents. Thus, it is possible to infer whether a current increase is due only to a reduced electrolyte resistance or to a change in the anodic corrosive activity. short-circuit of the working and counter electrodes.

\section{ZRA-arrangement}

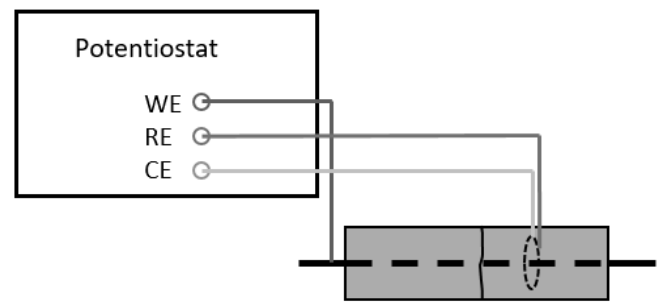

Fig. 6. Measuring arrangement (ZRA) in the experiment 


\section{Evaluation}

At the end of the experiment, the actual chloride contents within the concrete were determined photo-metrically inside the cracks, cf. Tab. 3.

Tab. 3. Determined chloride content within the crack of the specimen

\begin{tabular}{|c|c|}
\hline sample & chloride content \\
\hline$[-]$ & {$[\% / c$ by mass] } \\
\hline \hline $\mathbf{1 . 4 0 0 3 - 1}$ (reference) & $<0.20$ \\
\hline $\mathbf{1 . 4 0 0 3 - 2}$ & 0.43 \\
\hline $\mathbf{1 . 4 0 0 3 - 3}$ & 2.30 \\
\hline $\mathbf{1 . 4 0 0 3}-\mathbf{4}$ & 4.88 \\
\hline $\mathbf{1 . 4 0 0 3}-\mathbf{5}$ & 7.22 \\
\hline
\end{tabular}

In this experiments, a clear deviation from the results according to [16] was determined. In the lower chloride concentrations the results differ of up to a factor of two. Nevertheless, the extrapolated values are very close to the expected values, cf. Fig. 5.

Since the type of cement used (CEM I) was identical to that of [16], the influence of the type of cement as cause of the deviation can be excluded as well as the differences in w/c-ration (here $\mathrm{w} / \mathrm{c}=0.55$ and in [16] $\mathrm{w} / \mathrm{c}=0.50$ ), which would lead to higher chloride values in the more permeable pore structure. Higher chloride values would also arise, if the aforementioned "piggyback transport" within the dry concrete would be the cause of the deviation, due to concentrating chloride caused by drying. One of the possible causes could be the use of maximum grain size of $8 \mathrm{~mm}$ compared to the mortar tests on [16], which leads to a significantly longer chloride path in the cement paste around the larger aggregate.

However, the probable cause of the deviating values of [16] is assumed to be the duration of the exposed ponding. In these described experiments, the chloride solution did not last long enough in the crack region in order to obtain the values according to [16] (binding of the chlorides not yet completed). The well-matching values in the high chloride ranges can be explained by the lower dominance of bound chlorides.

However, the results of the preliminary tests with respect to chloride content serve as the basis for the subsequent investigations and provide good guidelines for adjusting the samples to sufficiently accurate chloride values in the crack region.

A challenge in the experimental evaluation of the element-currents results is the determination of the anode surface in the crack region. On the one hand there is imponderability with regard to the edge zone of the crack flanks. A mathematically determinable area of the steel within the crack is hard to define, as the participating area depends on too many influencing factors. The effective anode area for determining an element current density (element current in relation to the anodic steel surface) can only be a rough approximation. An accurate surface determination of the anodic area by assessing the pitting area is also hardly possible, as the time-depending formation of the pitting changes.

Thus the determination of the specific elementcurrent (current density) in this case was related to the reference rebar, which was charged with tap water and can be regarded as passive. The absolute current was supposed in relation to conventional passive current densities and an anode area was estimated of this.

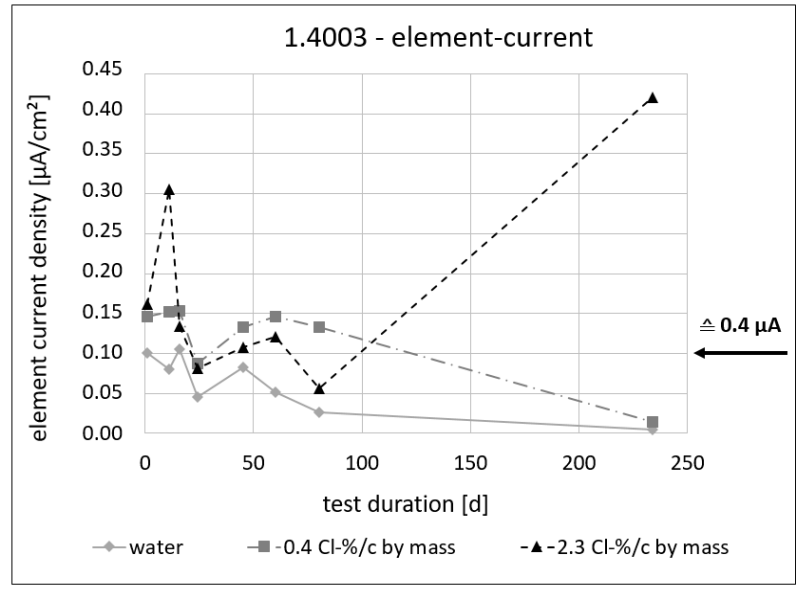

Fig. 7. Passive range 1.4003 - values shown as element-current density (linear)

The maximum of the absolute element-current was determined to be about $0.4 \mu \mathrm{A}$, cf. Fig. 7. This element current is approximately assumed to be the corrosion current of a passive reinforcement bar for the following analysis. The passive current density was set at $0.1 \mu \mathrm{A} / \mathrm{cm}^{2}$ based on [19]. This results in an anode area of:

$0.4 \mu \mathrm{A} / 0.1 \mu \mathrm{A} / \mathrm{cm}^{2}=4 \mathrm{~cm}^{2}=400 \mathrm{~mm}^{2}$.

This must be considered as a rough approximation, also because only the electrolyte with higher water content and thus higher conductivity is likely to provide charge transport between anode and cathode for the passive current density.

Noticeable in Fig. 7 is the increase in the second measured value on the test specimen with a chloride content of approx. $2.3 \%$ /c by mass. The increase by a factor of two for the initial measurement is not yet of any appreciable magnitude for corrosion currents, but could already argue for a first depassivation with a subsequent repassivation. After a storage time of up to 243 days after first application, a clear increase can be detected, which could be correlated with a corrosion pitting on the assessed rebar surface. The onset of corrosion without renewed chloride exposure may possibly have arisen due to a concentration of the chlorides on the crack flank. This would coincide with the location of the corrosion scar on the crack flank; cf. Fig. 11 and Fig. 12. At the edge of the crack, the concentration of chlorides is increasing due to desiccation. This increase is partly homogenized during the sampling for analysis over a neighbouring area. Nevertheless, due to the 
hygroscopicity of the salt, sufficiently high humidity at this point is to be expected for a corrosive attack.

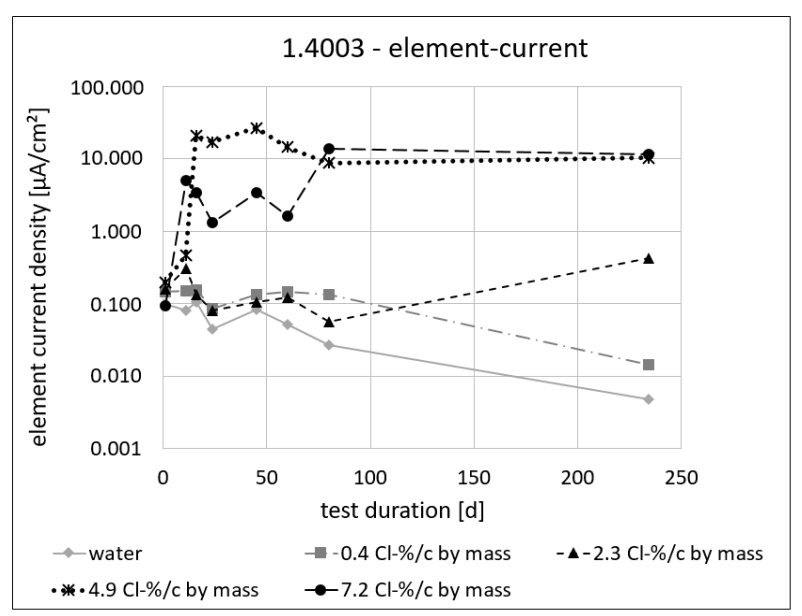

Fig. 8. 1.4003 - all current densities (logarithmic)

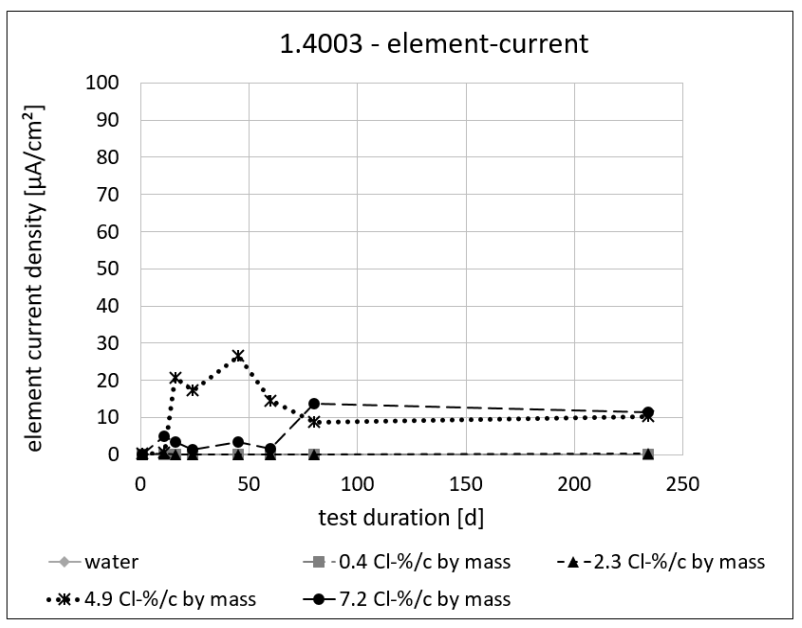

Fig. 9. 1.4003 - all current densities (linear)

If comparing the current densities of the 1.4003 with chloride contents at about $4.9 \%$ c by mass and $7.2 \% / \mathrm{c}$ by mass, a clear increase by up to a factor of 100 can be determined, assuring distinct pitting corrosion on the samples. Striking is the initially much higher corrosion rate with a chloride content of approx. $4.9 \% / \mathrm{c}$ by mass compared to $7.2 \% / \mathrm{c}$ by mass, which is aligned with increasing test duration, cf. Fig. 8 and Fig. 9.

In comparison between the element corrosion currents of the tested rebar 1.4003 (Fig. 9) with those of the B500B (Fig. 10), the significantly higher corrosion currents of the B500B are noticeable. Likewise, a corrosion initiation on the $\mathrm{B} 500 \mathrm{~B}$ is already detectable with a chloride content of about $0.4 \%$ /c by mass.

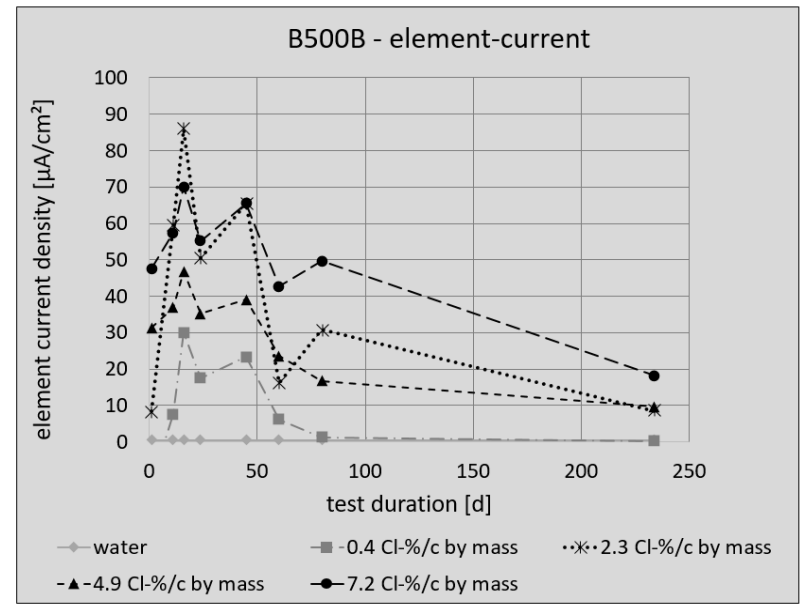

Fig. 10. B500B - all current densities (linear)

Tab. 4 below shows the current densities after a test period of 243 days as a function of the chloride content in the concrete.

Tab. 4. Current densities as a function of the chloride content in the concrete after 243 days of testing

\begin{tabular}{|c|c|c|}
\hline chloride content & \multicolumn{2}{|c|}{ current densities $\left[\mu \mathrm{A} / \mathrm{cm}^{2}\right]$} \\
\hline [\%/c by mass] & B500B & 1.4003 \\
\hline$<0.20$ & 0.03 & 0.005 \\
\hline 0.43 & 0.15 & 0.02 \\
\hline 2.30 & 8.45 & 0.42 \\
\hline 4.88 & 9.64 & 10.24 \\
\hline 7.22 & 18.14 & 11.50 \\
\hline
\end{tabular}

If the formation of pitting would not be considered and the corrosion pittings were mentally distributed on a uniform surface corrosion, in principle a corrosion rate (or temporal cross-sectional loss) using the Faraday's law could be determined. However, this value would not correspond to the actual removal rate and would highly underestimate the real cross sectional loss due to the formation of pitting. For this reason, the following description does not include the representation of a theoretical corrosion rate. Thus, a simple comparison of values is used, in which the corrosion currents can be interpreted as a factor. Tab. 5 shows the values of the current density as a multiple of the assumed passive current density of $0.1 \mu \mathrm{A} / \mathrm{cm}^{2}$. The following colour deposition was chosen for the intensity of the increase in corrosion current in correlation with the apparent absorption of the steels after the experiments:

\section{$<1 \mathrm{x}$ Passive current density $\Rightarrow$ no corrosion visible detectable}

$>1-10$ x passive current density

$\Rightarrow$ slight traces of corrosion visible detectable

$10 \mathrm{x}$ passive current density

$\Rightarrow$ pronounced traces of corrosion visible detectable 
Tab. 5. Factor of passive current density based on $0.1 \mu \mathrm{A} / \mathrm{cm}^{2}$ after 243 days of experiment

\begin{tabular}{|c||c|c|}
\hline \multicolumn{1}{|c||}{ chloride content } & \multicolumn{2}{c|}{ factor of passive current density } \\
\hline$[$ [\%/c by mass] & B500B & $\mathbf{1 . 4 0 0 3}$ \\
\hline \hline$<\mathbf{0 . 2 0}$ & 0.29 & 0.05 \\
\hline $\mathbf{0 . 4 3}$ & 1.51 & 0.15 \\
\hline $\mathbf{2 . 3 0}$ & 84.50 & 4.21 \\
\hline $\mathbf{4 . 8 8}$ & 96.38 & 102.43 \\
\hline $\mathbf{7 . 2 2}$ & 181.35 & 114.98 \\
\hline
\end{tabular}

As can be seen in Tab. 5, the B500B shows a significant increase in the corrosion current already at a chloride content of $0.43 \% / \mathrm{c}$ by mass, accompanied with a depassivation of the steel surface. The determined corrosion currents of the tested 1.4003 concrete steel increase, even at chloride levels of $0.43 \% / \mathrm{c}$ by mass, compared to the sample treated with tap water. However, the increase in the corrosion current can also result from the higher electrolyte conductivity in the crack region due to the salt application.

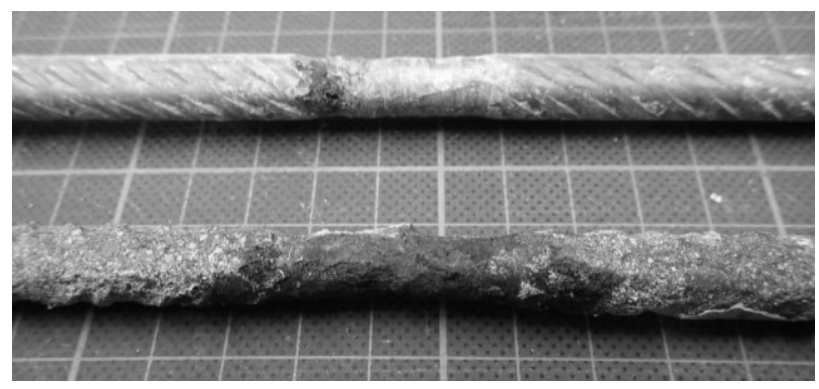

Fig. 11. Dismounted rebars (unpurified) from sample with chloride content of approx. $2.3 \% / \mathrm{c}$ by mass. Above: 1.4003 ; below: B500B

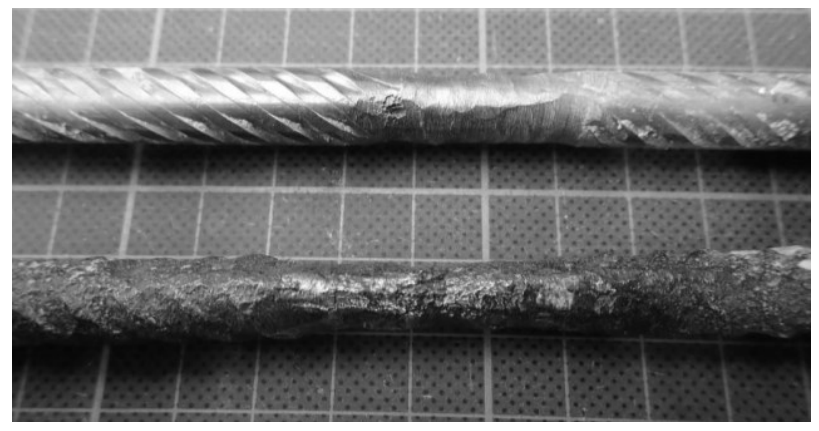

Fig. 12. Dismounted rebars (purified). from sample with chloride content of approx. $2.3 \% / \mathrm{c}$ by mass Above: 1.4003 ; below: B500B

\section{Limitations of the experimental setup}

The samples tested were used in pre-evaluations to enable a rough estimation of the critical chloride concentration limit of the 1.4003 in cracks. The selected number of samples is not suitable to cover scattering. The range of critical chloride values determined in these testing is not yet validated and minimized. However, despite the grinded surface of the steel and the crack formation due to yield deformation, the range of the critical chloride values is in accordance with test results reported in literature carried out with not grinded samples.

The presented preliminary tests serve as a good orientation for the following tests to better limit the critical corrosion-inducing chloride content in the crack region when using a 1.4003 . From the knowledge gained in the preliminary tests, the subsequent tests are optimized for reproducibility and practicality.

\section{Conclusion}

In carbonated concrete without chloride exposure, the 1.4003 proves to be stable in experiments from the literature. Comparing the tests from the literature with respect to the chloride resistance, a clear dependence of the determined critical chloride content of the 1.4003 on the surface quality, the type of cement and the experimental procedure is noticeable. The impact of mill scale, welds and ribbing, as well as the type of cement selected, may vary the results, in part, between a critical chloride level of well below $1 \% / \mathrm{c}$ by mass to over $5 \% / \mathrm{c}$ by mass of the tested rebar 1.4003 ("Top12"). If the 1.4003 reinforcement is in carbonated concrete with simultaneous chloride exposure, the corrosion resistance is significant lower.

The presented investigations also show that the corrosion resistance in the cracked RC-structures is lower than in non-cracked, chloride-containing concrete. The results of the correlation between submerged chloride concentrations to chloride contents within the concrete according to [16] prove that high concentration of chlorides in the exposure solution are necessary to obtain high chloride contents in the concrete. In direct contact with the steel, these high chloride contents lead to a faster depassivation of the reinforcement. In addition, the reinforcement in the crack area is not directly surrounded by a protective, alkaline concrete layer. In addition, with the selected, large crack width of $1.0 \mathrm{~mm}$, the first carbonation phenomena in the crack region may occur and thus a reduction in the $\mathrm{OH}^{-}$ concentration, which will reduce the critical chloride content. Insofar the investigations carried out with large crack widths are strongly on the safe side.

The preliminary tests showed an initiation of corrosion on the 1.4003 sample at $2.30 \%$ /c by mass using a concrete with CEM I cement, while the sample was still passive at $0.43 \% / \mathrm{c}$ by mass. The results of the corrosion current measurement, however, suggest that the limit established here is on the order of approx. $2 \% / \mathrm{c}$ by mass. As part of the further investigations, this limit should be verified more precisely with significantly more samples, different types of cement and $\mathrm{w} / \mathrm{c}$ ratios.

As a result, the following application areas prove to be effective for the 1.4003: the use in components with only a very small (possible) concrete cover, with the simultaneous avoidance of chloride contamination (e.g. facade elements) or the use in components with moderate chloride loading and sufficiently high concrete 
coverage, preventing the carbonation at the rebar during the service life (e.g. spray mist area on tunnel walls). The chloride content at which corrosion in cracks (of e.g. uncoated underground car park floor panels) for the 1.4003 can be excluded certainly, has yet to be demonstrated by the ongoing investigations.

\section{References}

1. Raupach M. Kosalla M., Korrosion der Bewehrung im Bereich von Trennrissen nach kurzzeitiger Chlorideinwirkung, 2. Jahrestagung und $\mathbf{5 5 .}$ Forschungskolloquium des DAfStb Düsseldorf, 11 (2014)

2. Deutscher Ausschuss für Stahlbeton, Richtlinie Schutz und Instandsetzung von Betonbauteilen, 10 (2001)

3. DIN Deutsches Institut für Normung e.V., DIN 4881: Reinforcing steels - Part 1: Grades, properties, marking, 8 (2009)

4. DIN Deutsches Institut für Normung e.V., DIN EN 10088-1:2014-12: Stainless steels - Part 1: List of stainless steels; German version EN 10088-1:2014, 12 (2014)

5. Greve-Dierfeld S. Bisschop J. Schiegg Y., Nichtrostende Bewehrungsstähle zur Verlängerung der korrosionsfreien Lebensdauer von Stahlbetonbauwerken. Beton und Stahlbetonbau 112, Heft 9 (2017)

6. Informationsstelle Edelstahl Rostfrei, Merkblatt 893 Edelstahl Rostfrei für die Wasserwirtschaft: Link: http://www.edelstahl-rostfrei.de/downloads/iser /MB_893.pdf, called last: 10 (2017)

7. Kunze E., Korrosion und Korrosionsschutz Band 5: Korrosion und Korrosionsschutz in verschiedenen Gebieten, Teil 2. WILEY-VCH (2001)

8. DIN Deutsches Institut für Normung e.V., DIN EN 10027-1: Designation systems for steels - Part 1: Steel names; German version EN 10027-1:2016; 1 (2017)

9. Swiss Steel, TOP12-500 Nichtrostender Betonstahl; Produktdatenblatt X2CrNi12 1.4003, Swiss Steel AG, http://www.swiss-steel.com/fileadmin/files/ swiss-steel.com/documents/dokumente/

Unternehmensentwicklung/Produktdatenblatt Top12-500_D-CH_PP9.pdf; called last: 10 (2017)
10. Nürnberger U. Beul W. Onuseit G., Korrosionsverhalten geschweißter nichtrostender Bewehrungsstähle in Beton. Bauingenieur 70 (1995) 73-81 und Werkstoffe und Korrosion 44 (1993) 159160

11. Schiegg Y. Hunkeler F. Voûte, C., Korrosionsbeständigkeit von nichtrostenden Betonstählen. Forschungsbericht zum Forschungsauftrag $\quad A G B \quad$ 2005/010,2012; Schweizerische Eidgenossenschaft, 11 (2012)

12. Bisschop, J. Schiegg, Y. Linden, C. Effect of rebar and cement type on the critical chloride content of reinforced concrete. Proceedings of EUROCORR, Montpellier (F), 9 (2016)

13. Schiegg Y., Hunkeler F., Keller D., Ungricht H., Maßnahmen zur Erhöhung der Dauerhaftigkeit Fortsetzung des Feldversuchs Naxberg, ASTRA Forschungsprojekt AGB 2005/01 (2017)

14. Fritz M., Vergleichende Untersuchungen zum chloridinduzierten Korrosionsverhalten der Bewehrungsstähle 1.4039 und 1.4003; Munich University of Applied Sciences; 9 (2017)

15. Leistikow, S., Thenen v. A., Pott E., Der Einfluss von Kaltverformung auf die Korrosion von fünf ferritischen Stählen unterschiedlichen Chromgehaltes in überhitztem Wasserdampf $\left(550^{\circ} \mathrm{C}, 70 \mathrm{at}\right)$, Kernforschungszentrum Karlsruhe, KFK 2120 (1975)

16. Tang, L., Chloride Transport in Concrete Measurement and Protection. Dissertation. Chalmers University of Technology Göteborg, Schweden, 10 (1996)

17. Gehlen C., Probabilistische Lebensdauerbemessung von Stahlbetonbauwerken - Zuverlässigkeitsbetrachtungen zur wirksamen Vermeidung von Bewehrungskorrosion, DAfStb, Heft $\mathbf{5 1 0}$ der Schriftenreihe, (2000)

18. Heitz E. Henkhaus R. Rahmel A., Korrosionskunde im Experiment, Untersuchungsverfahren Messtechnik - Aussagen, 2. überarbeitete Auflage; VCH Verlagsgesellschaft mbH (1990)

19. Chess P. M., Broomfield J. M., Cathodic Protection of Steel in Concrete and Masonry - Second Edition. CRC Press -Taylor \& Francis Group, A Spoon Press Book (2014) 